ISSN: 2162-3104 Print/ ISSN: 2166-3750 Online

Volume 8, Issue 1 (2018), pp. 151-178

(C) Journal of International Students

http://jistudents.org/

doi: 10.5281/zenodo.1134279

\title{
Qualitative Study on Chinese Students' Perception of U.S. University Life
}

\author{
Xiaokang Tang \\ Daniel A. Collier \\ Allison Witt \\ University of Illinois Urbana-Champaign, United States
}

\begin{abstract}
This qualitative research was conducted on Chinese international students preparing to study in the United States about their expectation and perception of American universities. It explored motivation for pursuing degrees in the United States, expectations of life in the United States, and plans post-graduation. Findings suggest that these students foresee U.S. classes to be rigorous due to two notable barriers: English proficiency issue and difference in learning environment. Furthermore, the students promoted desires to build relationships with domestic students but already internalized beliefs that this action was unlikely. They presumed that most networking would occur with co-nationals due to comfort and ease. Finally, parental expectations emerged as a significant factor that influence Chinese international students' desire to study in the United States and postgraduation plans.
\end{abstract}

Keywords: Chinese students, international students, higher education, policy, qualitative research

Within the last decade, the U.S. higher education system has been dramatically expanding international student enrollment. While international students have historically participated in U.S. post-secondary education, it was only recently that institutions have increased enrollment to supplement tuition revenue (Hu, 2011; Slaughter \& Cantwell, 2012). With international 
students contributing tens of billions of dollars in tuition and fees (Association of International Educators, 2013), luring more international students onto these campuses has become a primary business priority. However, as institutions scurry to grab a larger piece of this economic pie, previous research suggests that these campuses may have not developed or promoted adequate sociocultural accommodations (Collier \& Hernandez, 2015; Greenblatt, 2005; Hu \& Kuh, 2003; Trice, 2004; Ward, 2015).

Although there are calls for institutions to advance their development of these accommodations, what is often not taken into consideration is whether or not international students possess the desire to more deeply interact with American students. Some research, such as RoseRedwood and Rose-Redwood (2013), has found that international students self-segregate for various reasons, but there appears to be gaps in exploring international students' attitudes previous to enrolling in these institutions. Furthermore, as these institutions recruit more international students, public discourse on retention of these students after graduation has blossomed. Although previous research has suggested that over half of international students enrolled within the U.S. higher education system indicate they wish to stay and work in the U.S. post-graduation (Wadhwa, Saxenian, Freeman, \& Salkever, 2009), what is often left understudied is why international students wish to stay or if they choose to leave and for what reasons.

This qualitative study was conducted with Chinese students who were preparing to attend U.S. institutions in the future and were invited to a summer institute to learn about American post-secondary education. Through focus group interviews with these students, the study attempted to fill several research gaps. Firstly, we will look at the motivation for these students to consider a graduate program in the United States. Secondly, we explore how these students envision interacting with other international students and the domestic population. Finally, the study uncovers students' motivations to stay or leave the U.S. post-graduation.

\section{LITERATURE REVIEW}

\section{U.S. Institutions Recruiting Chinese Students}

\section{Parental Influences}

Parental influence is a primary driver and stressor for Chinese international students, particularly regarding pressure of academic performance (Fischer, 2015; McMahon, 2011; Wei et al., 2007; Yan \& 
Berliner, 2009; Yan \& Berliner, 2011). This pressure sometimes stems from financial reasons as Chinese culture values education as an important and worthy investment that encouraging students to feel the need to excel in school so that their parents' money is not wasted (Fischer, 2015; McMahon, 2011; Yan \& Berliner, 2009). At the same time, pressure may also generate from social and cultural norms as most Chinese students reside in a culture where family is honored through academic achievement (Kim, Atkinson, \& Yang, 1999; Kim, Li, \& Ng, 2005; Leong \& Chou, 1996; Sandhu, 1995). Additionally, the induction of guilt about parental sacrifices and the need to fulfill obligations is a significant value in typical Chinese families that may promote educational achievement (Zhang \& Carrasquillo, 1992).

While previous studies on Chinese students' relationship with parents mainly focus on academic pressure and social/emotional support, few studies have explored parents' influence on students' decision-making in terms of choosing to study abroad (Schulte \& Choudaha, 2014). Obviously, as parents place great importance and family honor on their children's academic performance, attending the highest ranked universities with the highest ranked programs should be an influential factor when deciding on a university. With many institutions in the U.S. lauded for their prestige and the overall system ranked at the top (Williams, Leahy, de Rassenfosse, \& Jensen, 2015), it only makes sense that parents would exert their influence to encourage their children to attend a top ranked U.S. institution. Although parents are influential to these students' collegiate decisions, research regarding parental influences beyond college are also understudied and under published. As previous research indicates that young Chinese adults remain close to their parents (Badger, Nelson, \& Barry, 2006), possibly this tight-knit relationship may impact post-college decisions such as deciding which country to work in or for how long.

\section{Better Schools, Better Job Opportunities}

In Mazzarol and Soutar's (2002) analysis of the push-pull factors influencing international students' decision-making process, awareness and academic reputation of the host country are believed to be critical factors. As the country that receives the most international students, the United States is generally seen as owning the world's best academic system. In the Institute of International Education's (IIE) report (2015), $82 \%$ of all respondents agreed that their study abroad decision was influenced by the fact that the U.S. offers a high quality higher education system and $79 \%$ of respondents agreed with the importance of a wide range of schools and 
programs. Yuan (2011) identified that internationally acclaimed scholars, advanced teaching and research facilities, and diverse academic environments contribute to interviewees' perception of American higher education's advantageous position in the world.

At the same time, students consider having their academic qualifications recognized by their future employers to be important, and gaining a degree in the U.S. is beneficial from this perspective. IIE (2015) found that

"Most Chinese students seeking to study abroad are seeking career preparation or advancement. The majority of Chinese students (75 percent) cited better career prospects as the primary reason to study abroad. The ability to make professional contacts was the second most frequently cited reason to study overseas (cited by 19 percent of respondents)." (IIE, 2015, pp.10-11)

Wan's (2001) study found that an American degree is important because it symbolizes proof that students are more capable academically and professionally. Other studies agree that the American degree is an emblem of prestige and superior to degrees earned in home countries, which provides one with the cultural capital attributed to study abroad experience that will help gain positions and promotions in home countries (Brzezinski 1994; Yan \& Berliner, 2011).

\section{Barriers That Affect Academic Performance and Social Development}

\section{Effects on Academic Performance}

Even though it is generally perceived that Chinese students' academic performance is outstanding, previous studies have identified various difficulties that may stymie this performance and social development on U.S. campuses. U.S. institutions have long wrestled with accommodating international students' comfort levels-especially with regard to breaking down the barriers and stressors associated with mastery of and confidence in English. Previous research has found that the stress associated with internalizing confidence in the dominant language and with adapting to the new educational environment hinders self-expected academic performance (Smith \& Khawaja, 2011). For instance, FassHolmes and Vaughn (2015) recognized that the increase in the international undergraduates has been accompanied by "a campus-wide generalization that these students, as a whole, are struggling academically and are 
increasingly at risk for academic probation, disqualification, and/or dismissal from the university" (p. 230).

One major theme in exploring this phenomenon is that second language anxiety can impact students' achievement on assignment writing, understanding lectures, oral and written examinations, and the ability to ask questions in class (Chen, 1999; Leong, 2015; Mori, 2000; Yuan, 2011). Not only may these students possess self-internalized lower confidence, U.S. institutions are not always welcoming environments (Greenblatt, 2005) and in some spaces these students are faced with ridicule of their language proficiency - a process that drives these students to believe there is a lack of institutional support and promotes diminished confidence in abilities and capabilities (Cho, 2009; Lee \& Rice, 2007). In recognition of this issue, institutions have developed various units (Ward, 2015) and programs to assist these students in becoming more masterful with English and in gaining confidence in interacting with staff, faculty, and peers; but these units are still widely lacking in services and capabilities (Collier \& Hernandez, 2015).

Additional to language proficiency, the difference between education systems and teaching styles is also a significant obstacle in Chinese international students' acculturation process. Regarding the educational experience of Asian international students in the U.S., participants stated that it was difficult to adjust to the interactive teaching style and critical thinking approach to learning (Liberman, 1994). Such difficulty may stem from a difference in teaching style and classroom environment. For instance, American education tends to emphasize individual autonomy, and thus, accordingly minimizes the power teachers exert over students. Yet Chinese students may have a higher expectation of the instructor's participation in their academic activities and are more comfortable with the "authoritarian instruction" (Jin \& Cortazzi, 1991; Yan $\&$ Berliner, 2009). Additionally, Chinese students hardly ever experience situations where a teacher and student are considered nearly equal (Wan, 2001). Classroom culture in China typically requires a respectful and silent environment. Therefore, Chinese students may experience dissonance when American teachers encourage active participation. This internal dissonance could lead to anxiety and discomfort for these students (Bertram, Poulakis, Elsasser \& Kumar, 2014; Wang \& Mallinckrodt, 2006; Yeh \& Inose, 2003,)

Although academic performance is obviously an important piece of international students' growth, U.S. institutions also place great emphasis on social growth. Some of the difficulties Chinese students perceive in social life are similar to their academic life, such as second language proficiency 
issue. Yet many distinct problems arise in social life as students obtain different expectations about socializing on an American campus. Whereas international students have to learn to integrate with their host campus in their academic life, they have more diverse choices when it comes to social support in their personal life.

\section{Homogeny and Desire To Network Out}

In discussing international students' social support, previous research has identified that Chinese students value co-national peers as an important support resource for various reasons. Researchers unearthed that Chinese international students generally have difficulty making connections with American students, university staff, and with the local community (Heikenheimo \& Shute, 1986; Trice, 2002; Ward, Bochner \& Furnham, 2001; Zhang \& Brunton, 2007). While Chinese international students communicate with American professors and peers in academic life, these students remain segregated in social life. This segregation may be a result of losing established social networks.

With these networks fractured, international students may no longer receive the level of social support from close friends and family members whom they sought advice and comfort from while in China (Lee, Koeske \& Sales, 2004; Smith \& Khawaja, 2011). Therefore, Chinese peers serve as a valuable source for many Chinese international students in that these students help each other maintain strong connections with their home culture and language (Du \& Wei, 2015; Ye, 2006; Yuan, 2011). Because these students share aspects of the same culture and similar experiences on U.S. campuses, this common bond often enables Chinese students to share mutual frustrations as well as develop more comfortable coping strategies (Leong, 2015; Ye, 2006). At the same time, Du and Wei (2015) attributed Chinese students' strong need for co-national friends to Chinese traditional culture that values collectivism (Triandis, 1989). The increase in numbers of Chinese students enrolled in U.S. universities facilitates formation of homogenous social circles and participation in co-national circles as an alternative to participating in mainstream campus culture (Du \& Wei, 2015; Rose-Redwood \& Rose-Redwood, 2013).

Emerging research has recently suggested that some Chinese students express the wish to network with domestic students before arrival or at the beginning of their stay (Bertram et al., 2014; Yuan, 2011). However, for various reasons many students fail in this process. One recent study indicated that some international students tend to revert to segregation 
after negative interactions with the domestic population. Although not all of these interactions were intentionally negative, however, some were unsavory enough to promote the sustained division. Additionally, within the same study of those who claimed to interact with Americans, only a small population suggested that they had developed close friendships with Americans (Rose-Redwood \& Rose-Redwood, 2013).

Although homogeneity provides comfort and a safe space for international students, campuses must work harder to encourage diverse interactions. Homogeneity presents problems with personal growth (Huh \& Kuh, 2003; Watt et al., 2013), and diverse interactions can have positive outcomes for international students such as increased self-efficacy, higher grades, and improved satisfaction with the collegiate experience (Webber, Krylow, \& Zang, 2013). Possibly through more research on Chinese students' expectations of interaction with domestic students, researchers could better assist campuses with encouraging both development of homogenetic and diverse social networks.

\section{Rationale}

Although previous research has examined various aspects of Chinese international students in the U.S., few studies specifically addressed Chinese students' perceptions of American higher education before their arrival. During summer 2015, researchers conducted a qualitative study on a group of Chinese college students who were planning to study in U.S. graduate schools. We explored how Chinese internationals students felt about the American higher education system. Specifically, we were interested in learning about the main factors that influenced their decisions to study abroad, how they imagined and what they expected of their experience on an American campus, and how they viewed their postgraduate plans.

\section{RESEARCH METHOD}

\section{Site and Sample}

Data was collected at a large research university in the Midwestern United States with the approval of the university's IRB office. The study recruited Chinese students who were currently in Chinese colleges with the intent to study in U.S. in the future, and were engaged in a summer institute designed to expose these students to American culture and to American 
higher education. Students engaged in a variety of workshops, class experiences, and cultural interactions. These students hailed from various rural and urban areas in China. A secondary business was utilized to recruit these students for this experience. However, while diverse geographically, the students were chosen to participate in this institute based on two majors: (a) business or (b) engineering. To the host university, these two majors are important and hold top ten national rankings; therefore, recruitment of top talent into these majors is paramount for the host university. In total, there were 60 students - 51 females and nine males. Forty of them majors in business, 16 in mechanical engineering, one in education, one in psychology, and one in architecture

\section{Focus Group}

Focus groups were conducted roughly half-way through the program. Each focus group consisted of 10 to 12 students-which Krueger and Casey (2015) suggest to be the limits. The focus groups were conducted in Mandarin by Mandarin fluent employees of the Office of International Programs in the College of Education. For consistency, each focus group leader was given a list of questions to follow. These questions asked students how they felt about the United States and American education, the educational experience they were currently engaged in, the reasons why they desired to come to an American campus, how they envisioned their sociallife to be while at an American campus, and finally post-graduation plans. Generally, these focus groups' interviews lasted 45-60 min. Records of responses were captured via auditory recordings.

\section{Data Analysis}

After the conclusion of the institute, these Mandarin fluent employees of the Office of International Programs transcribed the focus group responses and translated the transcript into English. When transcriptions were completed, the first and second researcher began analyzing the data. Initially, the first and second author held several meetings to identify and debate the process of identifying trends in the data. The authors agreed that thematic analysis was the appropriate function; thematic analysis has been established as an effective method in "identifying, analyzing, and reporting patterns within data" (Braun \& Clarke, 2008, p. 79). Once the first two researchers agreed to this approach, they fleshed out the first several overarching themes together. After the 
process was solidified, the researchers decided to work concurrently but separately; the first two researchers then brought different documents to the next meeting. The common themes were located and the differing themes were debated and either accepted as is, modified, or removed as a theme. The third researcher acted as a referee for instances where the first two could not agree on the theme. This process is labeled "multiple coding" and is an important step in developing refined themes as well as triangulation (Barbour, 2001).

\section{RESULTS}

\section{Academic Rigor}

Most interviewees' responses regarding their expected academic performance in an American institution aligned with the academic difficulties mentioned in the literature review (Fass-Holmes \& Vaughn, 2015; Smith \& Khawaja, 2011). Participants often recognized difficulties in achieving academic success in the United States, as they believed that courses were more rigorous than those in China. For example, one student said:

"The coursework is more difficult in the U.S. Is it not too easy to learn stuff here? The universities here must have courses that are deeper and more difficult. They learn by discussion between themselves and stuff. It's not like us, like the easy classes we have."

Because of this belief, many students perceived that most of their time would be spent on study and thus have few opportunities to socialize:

"I don't think there is social life for me when studying in U.S. I think you need to study all the time from Monday to Friday. And then do homework on Saturday. Maybe do some laundry on Sunday and that's it."

Additionally, participants recognized two significant barriers towards academic success. First, students suggested that English was a major barrier of success. Second, interviewees also discussed how American classroom culture was significantly different from Chinese classrooms. Students expressed that these differences may hinder adjustments to the expectations and classroom environments. Participants believed that Chinese college classrooms had lower requirements for students' autonomy than American classes; thus, resulting in self-developed perceptions that 
Chinese students were less motivated to study and may not be prepared for greater autonomy or American expectations:

"In China my professors do not have a high requirement. Like me, I always force myself to study in the library because I'm going to take the TOEFL test. And I think coming here...the schedule is pretty tight every week."

"The students need to be more autonomous in terms of studying (in U.S.). The pace of teaching here are faster, so we need to spend more time studying on our own."

"There are more interactions between people in the classroom [in America]. In China, normally the will be teacher speaking all the time... You sleep a lot in classes in China. There are three or four classes a week that you just sleep. I'm just saying what's true."

Interviewees also identified that Chinese universities' less rigorous academic culture was a primary rationale towards desiring to study in the United States. These students perceived that academic rigor was an important resource that U.S. higher education possessed - which not only is represented via more regarded degrees but also more worthwhile collegiate experiences.

"I want to study in a good school, with good ranking and stuff. It must be better than my current school, right? Something like top 30, you know? Studying at my current school now is just a waste of time."

Some interviewees also suggested that a school's rank also reflected the abilities and work ethic of the students on campus. Many agreed that Chinese college was too easy for students to receive a good quality education and desired to be on campuses similar to the one where this summer institute was held:

"Like when I was preparing for the exams, I was the only student doing this. Nobody else. This feeling was very strange. But here you can see people are all engaged in their own business and everyone is very busy. It's completely different."

Interviewees had expected various types of difficulties they might encounter in their future study abroad experience. Language proficiency was identified by many interviewees to be an important issue, as the literature has previously discussed (Chen, 1999; Leong, 2015; Mori, 2000; Yuan, 2011). At the same time, interviewees pointed out many aspects that they 
perceived to be essential differences between Chinese and American higher education. They believed that academic life in U.S. colleges was more rigorous and demanding than in China, which was both the reason they wanted to pursue an American education and the reason they were worried about their academic performance.

\section{Homogeny and Desire To Network}

When the researchers asked the question "who do you think you will hang out the most with," the interviewees provided relatively similar answers. Although many responses seemly agreed with previous findings about Chinese students' preference for co-national social support (Du \& Wei, 2015; Ye, 2006; Yuan, 2011), participants in this study expressed desires to interact with people outside of their co-national friend circle. On the other hand, following their desire to network out, many hypothesized that various factors and challenges will impede them from constructing lasting friendships with people from other countries.

Interviewees considered co-national friends to be an important resource of social support. Even though these students have not yet studied on an American campus, they have already constructed expectations about social relationships based on personal beliefs and interactions with people who have. Due to the large number of Chinese students studying abroad, interviewees suggested that relatives, former classmates and friends had previously discussed their experiences of living and studying in the U.S. The participants relayed that those whom they have discussed studying abroad with suggested that building a network of co-national friends is highly important, because engagement with and integration into U.S. communities may be unlikely. For example, one interviewee said:

"I think I will still be hanging out mostly with international students. I have never experienced this, but I heard that it will still be difficult to be involved with the local community. The fact is that Chinese people's life style and religious belief are not...like...it's very different. It feels like two different worlds. It should be pretty hard to be assimilated. But you will still have some friends that are foreigners. But it would be quite impossible to be really part of them."

Interviewees also mentioned the importance of seeking assistance from peers who have the similar backgrounds, for example: 
"I think I would first join the association that has people who come from same place. Then if I have any question, I can ask senior students for their suggestions. It could be a faster way to just ask for help from someone who has had similar experience."

Generally, these participants held beliefs that seeking guidance from co-nationals was simply "more natural" and "more comfortable." These findings are unsurprising and reinforce previous findings suggesting that students prefer the comfort of interacting with others from similar sociocultural backgrounds (Leong, 2015; Rose-Redwood \& Rose-Redwood, 2013; Ye, 2006).

However, while these students generally expressed desires to build networks with co-nationals, many of the interviewees articulated the strong desire to interact with people from other countries and the local community. Participants indicated that building networks of co-nationals was a necessary, almost forced survival mechanism, most desired to more deeply interact and socialize with Americans. Some stated that developing relationships with Americans is important for improving the proficiency in English. Others mentioned a desire to learn more about American culture. For instance, one interviewee said that:

"I would like to try to know people from different places around the world. Since America has attracted people from different countries, it would be a good chance to know not only the local students but students from different countries as well."

Another interviewee talked about how she would try to avoid staying with Chinese students if possible:

"But if I could, I might want to stay away from Chinese students. In my college, I do not like to stay with people from the same province even if we have similar background in my current school. It is because we are all pretty similar, so I would like to experience something different to find those people who are not alike. I think I would like to be friends with people from different country."

While participants possessed desires to interact with Americans, they generally foresaw difficulties in actualizing this goals and in building long-lasting friendships with Americans. One primary concern was in regards to language and cultural barriers.

"Because...since you are here, of course you want to be with other people in order to speak in English, learn about their culture and 
something. But eventually you will find yourself unable to open your mouth. So the result will be hanging out with Chinese."

"Ideally I wish I can meet people from different cultures. But in the beginning language would be a problem, as a result I think I would spend more time with Chinese students."

Previous researchers pointed out that students are reluctant to interact in the language that they are not native speaker in, as speaking foreign language makes them feel like being treated as a baby instead of an adult (Leong, 2015; Yan \& Berliner, 2009, 2011). In addition to language barrier, cultural differences may also create difficulties for international students to socialize outside of their co-national circle.

"I think it is hard to make a real good friend if we do not share the same life experiences. You may have (American) friends, but not close friends."

"Sometimes it's just hard to understand the joke told by people from different cultures."

Overall, interviewees believed that building friendships with Americans was important to their social growth. However, due to perceived difficulties in overcoming sociocultural barriers in building these friendships-many students already held beliefs that cultivating these relationships was unlikely: "This is actually a very serious problem. What I heard is that people cannot really make friends with foreigners when they study abroad."

\section{Parental Influence on Post-Graduation Choice}

The final exploration of this research was focused on expectations regarding students' post-graduation options. We asked these Chinese students whether they wanted to develop their careers in China, America, or elsewhere. Most of our interviewees were college sophomores and juniors, who may have not contemplated their exact career path thoroughly, but many had thoughts regarding location choice after obtaining a graduate degree from an American university. Interestingly, these students suggested that one of the most significant factors affecting their post-graduation choices was parental influence.

For students who planned to return to China immediately after graduation, being close to parents and family was the most frequently mentioned reason. Interviewees suggested that they were the single child of their family, and due to this situation they would not ask others to share the 
responsibility of taking care of and accompanying their parents. Supporting the elderly is long valued in Chinese culture and is considered to be children's responsibility (Sun, 2002; Yang, 1996). We present several examples of when students summarized the importance of parental relationships when exploring post-graduation options:

"I will go back to China. Not just China, I would like to go back to my hometown, the province where I am from. I do not want to stay away from my parents. It is fine that I just study abroad, but not a long time away from them."

"I want to stay close to my family. My mom doesn't want me to be too far away from them. My mom...she doesn't like...she likes the way...She wants to be with a lot of old friends and relatives. If I want to take her to U.S. with me, she will not be happy."

Almost all interviewees expressed the necessity for them to take parents into consideration about their post-graduation plans.

Not all students desired an immediate return to China, but even for students who desired to remain in the U.S. post-graduation, parents affected the perceived length of stay. Students considered working experience in the United States as an add-on to the value of studying abroad. In other words, practical experience would guarantee or even increase the prestige of the American degree in in Chinese job market, which appeared to be the most important reason for them to come to the United States in the first place. Nonetheless, many expected to return to China, and similar to students mentioned above, their reason for going back was mostly about parents and family.

"There are many people who have studied abroad. If there is no working experience, it feels like (I) wouldn't be competitive enough. So it will be better to get some working experience here before going back. Three to five years. Yes. And I will be closer to my parents."

"I would like to work in the U.S. for couple years then go back to China. Since I'm the only child in the family, we want to stay closer as possible. However, it would be better to gain some working experience in the U.S. companies after graduate school in the U.S."

Other than parents, students also mentioned other family related factors such as getting settled down and getting married would be easier in their home country. 
Lastly, for interviewees who stated that they would want to stay in the United States after earning a degree, parental influence was still important in this decision:

"My parents really want to come here. Yeah. So their plan is that I should stay as long as I'm capable of and then bring them over here as well."

"My parents are counting on me. Yes they are picturing a wonderful life ahead (in the U.S.)."

Interestingly, based on reflection and notes, it appears that the two students cited above did not appear to be enthusiastic about immigrating to the United States. However, these individuals expressed a willingness to comply as it was their parents' wish. Clearly, other factors may contribute to these students' decisions to return to China or remain in the United States, but this research has uncovered that parental influence may be a dominant theme in this decision.

\section{DISCUSSION}

\section{Academic Difficulties}

The present study demonstrates that the American academic environment is perceived to be more rigorous than the Chinese one, which may cause barriers for Chinese international students' adjustment. While this research shows the contradictory side of the long-term model minority stereotype of Asian Americans, it also brings up suggestions for international students' recruitment and admission.

Both the literature review and our study's results indicate that Chinese students are expected to encounter various types of academic difficulties in U.S. colleges. Unlike the stereotypical impression that Asians generally excel in academics, Chinese international students are required to overcome many difficulties including language proficiency, different teaching style, different evaluation process, and more in order to keep up with their American peers. Therefore, courses with large numbers of Chinese international students may need to be revised in order to better accommodate students' studying habits and adjust the classroom dynamic.

We suggest that instructors implement policies which encourage each student to engage in two mandatory office hours - one in the first two weeks of the course and one after the mid-term. Such policies will help Chinese international students forge relationships with the instructor and 
will help the instructor understand some of the reservations that said students may possess (Jaasma \& Koper, 1999; Lamport, 1993). These meetings may open the door for Chinese international students to request additional office hour meetings with the instructor which would be beneficial for both the student and instructor. The students may be able to gauge measurements of academic performance and adhere to class expectations, while the increased personalized exposure of these students could assist the instructor in creating a more welcoming environment and with reconstructing classroom expectations to facilitate non-American students.

Anecdotally, in the second author's experience, similar meetings have increased his awareness for developing more inclusive classroom engagements and in recognizing common performance trends in Chinese international students' graded deliverables. Obviously, such accommodations may be burdensome for college instructors and advisors. However, if U.S. institutions continue to engage in the business of enrolling these students en masse and for business purposes, such changes will be paramount to ensure that Chinese international students are given proper opportunity to succeed as equally as is granted to domestic American counterparts.

\section{Social Networking}

As the number of international students is increasing on U.S. campuses, more programs have been developed to assist international students to integrate into the campus culture. This study, however, shows that interviewees still expect their social circle in the United States to be centered on co-national peers because attempts to network out may end up with failure. These beliefs indicate that better integration programs need to be designed by universities. As suggested by previous literature, offices that serve international students generally emphasize regulatory and business services processes over cultural and social programming (Collier \& Hernandez, 2015). As a result, students go to these offices for help on regulatory issues such as immigration documents, registration procedures, and so on. Yet, they may not know how to improve their ability to socialize with American peers and broaden their social networks. In large universities with great number of international students, integration programs are being developed by different offices and cultural centers, but these programs are, in many ways, seemingly ineffective (Ward, 2015). 
Interviewees' responses also remind us that not all international students are expecting full integration into the American campus culture. Some Chinese students do not view socializing with the mainstream society to be a necessary component of their study abroad experience. Their major focus is academic success and thus the degree of integration is enough as long as they can get their degree and a good GPA. For these students, their demand for American friends may be very low and social interactions with Americans would only serve for necessary daily life needs. Their university's integration programs may simply not be appealing for them, and it does not seem to be imperative for them to attend such programs.

At the same time, international students view their co-national peers to be the best resource to receive valuable information about how to survive in a foreign country. In some universities, international students' own organization has been playing an important role in their social support. Conational peers perform various functions that could hardly be replaced by university offices; therefore, social support provided by co-national peers should be valued under all circumstances.

\section{Parental Influences}

The post-graduation question generated our findings that were very different from our previous impressions. As prospective students, the interviewees presented a post-graduation expectation that was very different from the literature's findings. Instead of wishing to work and stay in America (Wadhwa et al., 2009), the interviewees expressed the importance of accompanying parents in their home country. This suggests that either not all Chinese students aim at staying in America after graduation, or their future plan changes a lot during the time in college. We do not know which one of the suggestions or maybe even both are correct in depicting the students' post-graduation plan. Yet we learned that this decision is highly linked with their parents' preference for future living conditions. It has been shown that universities have recognized the importance of parental influences on students' college choices (Williams et al., 2015). This study's result implies that the influence on career choices can hardly be overlooked either. For American companies that seek Chinese international graduates as potential employees, it may be beneficial to take the parents' factor into consideration. 


\section{LIMITATIONS AND FUTURE RESEARCH}

This research was conducted on students who were preparing for graduate studies in the United States, a generally unique population. While our findings support previous studies, differences between graduate students and undergraduate students may exist. Additionally, this sample was interested in studying only in top-tier programs at research heavy institutions; therefore, sample limitations in this respect may exist and differences between this type of students and those less interested in rank and prestige may also exist. While this study holds certain limitations, future research could be conducted to find these differences or explore similarities. Both qualitative and quantitative methodologies could be utilized to more deeply understand beliefs surrounding academic rigor between Chinese and American post-secondary education, networking with American students, and the influence parents hold on post-graduation options. Possibly a quantitatively focused survey could expand on the role that parents have when deciding post-graduation options. A more focused qualitative study could explore whether or not the challenges in developing friendships with American students were evident, and if so how did students overcome such or were they even able to?

\section{CONCLUSION}

The growing number of Chinese international students in the U.S. has brought a lot of discussion around the topic of how to better serve and integrate this group. This study explored the issue from the standpoint of prospective students, and explored how students' expectations can be different from or the same as what has been uncovered in existing literature. The study's results show that it is very possible that Chinese internationals students may possess different goals from what American universities typically expect.

For instance, Chinese international students may not think social integration to be crucial in collegiate experience; they also might view accompanying parents as a very important consideration in their postgraduation plans. This brings up the question for both Chinese students and American universities of who defines what successful study abroad experiences are when conflicting expectations take place. As many American universities are recruiting Chinese international students for financial reasons, it seems to be necessary to satisfy these students. In that sense, would it be unnecessary or even wrong if our international student 
service offices are making efforts to integrate all Chinese students into the American campus culture, if some of them do not consider integration into American culture appealing? Are professors expected to make adjustments in their teaching methods and curriculum to accommodate the difference between Chinese and American teaching styles? Should the career service centers incorporate more cultural components into their program designs?

However, to what extent should the universities accommodate? As the interviewees in this study pointed out, American higher education is appealing to them not only because the degree could make them more competitive in future job markets, but also due to the curiosities that these students have in differences between their culture and America's. If the American universities make all kinds of accommodations, how could they remain distinct and prestigious among the world's higher education institutions? These questions remain to be answered.

\section{REFERENCES}

Altbach, P. G. (2004). Globalisation and the university: myths and realities in an unequal world. Tertiary Education and Management, 10(1), 3-25. doi: 10.1023/b:team.0000012239.55136.4b

Association of International Educators. (2013). The economic benefits of international students to the U.S. contributed \$24 billion in 2012-2013; supports 313,000 jobs. Retrieved from http://www.iie.org/ /media/ Files/Corporate/Open-Doors/Special-Reports/NAFSA-Economic-BenefitsInternational\%20Students-2013.ashx

Badger, S., Nelson, L. J., \& Barry, C. M. (2006). Perceptions of the transition to adulthood among Chinese and American emerging adults. International Journal of Behavioral Development, 30(1), 84-93. doi: 10.1177/ 0165025406062128

Barbour, R. S. (2001). Checklists for improving rigour in qualitative research: A case of the tail wagging the $\operatorname{dog}$ ? $B M J, 322(7294), 1115-1117$. doi: 10.1136/bmj.322.7294.1115

Bertram, D. M., Poulakis, M., Elsasser, B. S., \& Kumar, E. (2014). Social support and acculturation in Chinese international students. Journal of Multicultural Counseling and Development, 42(2), 107-124. doi: 10.1002/ j.2161-1912.2014.00048.x

Braun, V., \& Clarke, V. (2006). Using thematic analysis in psychology. Qualitative Research in Psychology, 3(2), 77-101. doi: 10.1191/1478088706qp063oa

Brzezinski, M. (1994). Migration \& opportunity: A qualitative understanding of the Chinese student brain drain phenomena (NASFA working paper, No. 41). Washington, DC: NASFA. 
Chen, C. P. (1999). Common stressors among international college students: Research and counseling implications. Journal of College Counseling, 2, 49-65. doi: 10.1002/j.2161-1882.1999.tb00142.x

Cho, P. L. (2009). Welcome to America?: The perceptions of discrimination experienced by international students (Doctoral dissertation). Scholar Works@UNO (Paper No. 918). Retrieved from http:// scholarworks. uno.edu/cgi/viewcontent.cgi?article? 1899\&context?td

Collier, D. A., \& Hernandez, X. J. (2015). Tatemae and honne: Interpreting the theory versus practice of international student development and outreach. Journal of Diversity in Higher Education. Advance online publication. doi: $10.1037 /$ dhe 0000011

Du, Y., \& Wei, M. (2015). Acculturation, enculturation, social connectedness, and subjective well-being among Chinese international students. The Counseling Psychologist, 43(2), 299-325. doi: 10.1177/ 0011000014565712

Fass-Holmes, B., \& Vaughn, A. (2015). Evidence that international undergraduates can succeed academically despite struggling with English barrier. Journal of International Students, 5(3), 228-243.

Fischer, K. (2013). A freshman year, far from home. Chronicle of Higher Education, 40(1). Retrieved from http://chronicle.com/article/A-FreshmanYear-Far-From-Home/141303/

Greenblatt, S. (2005). International students and diversity in American higher education: Implications for internationalization. International Journal of Diversity in Organisations, Communities and Nations, 5, 163-171.

Heikenheimo, P. S., \& Shute, J. C. M. (1986). The adaptation of foreign students: Student views and institutional implications. Journal of College Student Personnel, 27, 399-406.

$\mathrm{Hu}, \mathrm{S} .$, \& Kuh, G. D. (2003). Diversity experiences and college student learning personal development. Journal of College Student Development, 44, 320334. doi: $10.1353 / \mathrm{csd} .2003 .0026$

Hui, C. H. (1988). Measurement of individualism-collectivism. Journal of Research in Personality, 22, 17-36. doi: 10.1016/0092-6566(88)90022-0

Institute of International Education. (2015). What international students think about U.S. higher education: attitudes and perceptions of prospective students from around the world. Retrieved from https://www.iie.org/Researchand-Insights/Publications/What-International-Students-Think-About-USHigher-Education

Jaasma, M. A., \& Koper, R. J. (1999). The relationship of student-faculty out-of-class communication to instructor immediacy and trust and to student motivation. Communication Education, 48(1), 41-47. doi: 10.1080/ 03634529909379151

Jin, L., \& Cortazzi, M. (1991). Cultural orientation and academic language use. Paper presented at the annual meetings of the British Association of Applied Linguistics, Trevelyan College, University of Durham. 
Kim, B. S. K., Atkinson, D. R.,\& Yang, P. H. (1999). The Asian American values scale: Development, factor analysis, validation, and reliability. Journal of Counseling Psychology, 46, 342-352. https://www.researchgate.net/ publication/232504603_The_Asian_Values_Scale_Development_Factor_ Analysis_Validation_and_Reliability

Kim, B. S. K., Li, L. C., \& N $\bar{N}$, G. F. (2005). The Asian American values scalemultidimensional: Development, reliability, and validity. Cultural Diversity and Ethnic Minority Psychology, 11, 187-201. http://www.ncbi. nlm.nih.gov/pubmed/16117587

Krueger, R. A., \& Casey, M. A. (2000). Focus groups: A practical guide for applied research. Thousand Oaks, CA: Sage.

Lamport, M. (1993). Student-faculty interaction and the effect on college student outcomes: A review of the literature. Adolescence, 28(112), 971. http://www.ncbi.nlm.nih.gov/pubmed/8266849

Lee, J. J., \& Rice, C. (2007). Welcome to America? International student perceptions of discrimination. Higher Education, 53, 381-409. doi: 10.1007/s10734-005-4508-3

Lee, J., Koeske, G. F., \& Sales, E. (2004). Social support buffering of acculturative stress: A study of mental health symptoms among Korean international students. International Journal of Intercultural Relations, 28(5), 399-414. doi: $10.1016 /$ j.ijintrel.2004.08.005

Leong, F. T. L., \& Chou, E. L. (1996). Counseling international students. In P. B. Pedersen, J. G. Draguns, W. J. Lonner, \& J. E. Trimble (Eds.), Counseling across cultures (4th ed., pp. 210-242). Thousand Oaks, CA: Sage.

Leong, P., (2015). Coming to America: assessing the patterns of acculturation, friendship formation, and the academic experiences of international students at a U.S. College. Journal of International Students, 5(4), 459474. http://files.eric.ed.gov/fulltext/EJ1066267.pdf

Liberman, K. (1994). Asian student perspectives on American university instruction. International Journal of Intercultural Relations, 18, 173-192. doi: 10.1016/0147-1767(94)90027-2

Mazzarol, T., \& Soutar, G. N. (2002). "Push-pull" factors influencing international student destination choice. International Journal of Educational Management, 16(2), 82-90. doi: 10.1108/09513540210418403

Mcmahon, P. (2011). Chinese voices: Chinese learners and their experiences of living and studying in the United Kingdom. Journal of Higher Education Policy and Management, 33(4), 401-414. doi: 10.1080/ 1360080x.2011.585739

Mori, S. (2000). Addressing the mental health concerns of international students. Journal of Counseling and Development, 78, 137-144. doi: 10.1002/ j.1556-6676.2000.tb02571.x

Rose-Redwood, C. R., \& Rose-Redwood, R. S. (2013). Self-segregation or global mixing?: Social interactions and the international student experience. 
Journal of College Student Development, 54, 413-429. doi: 10.1353/ csd.2013.0062

Samovar, L. A., \& Porter, R. E. (1991). Communication between cultures. Belmont, CA: Wadsworth.

Sandhu, D. S. (1995). An examination of the psychological needs of the international students: Implications for counseling and psychotherapy. International Journal for the Advancement of Counseling, 17, 229-239. doi: $10.1007 / \mathrm{bf} 01407739$

Schulte, S. \& Choudaha, R. (2014). Improving the experiences of international students, Change: The Magazine of Higher Learning, 46(6), 52-58. doi: 10.1080/00091383.2014.969184

Sellar, S. \& Lingard, B. (2013) Looking east: Shanghai, PISA 2009 and the reconstitution of reference societies in the global education policy field, Comparative Education, 49(4), 464-485. doi: 10.1080/03050068.2013. 770943

Slaughter, S., \& Cantwell, B. (2012). Transatlantic moves to the market: The United States and the European Union. Higher Education, 63, 583-606. doi: 10.1007/s10734-011-9460-9

Smith, R. A., \& Khawaja, N. G. (2011). A review of the acculturation experiences of international students. International Journal of Intercultural Relations, 35(6), 699-713. doi: 10.1016/j.ijintrel.2011.08.004

Stigler, J. W., Smith, S., \& Mao, L. W. (1985). The self-perception of competence by Chinese children, Child Development, 56, 1259-1270. doi: 10.2307/ 1130241

Sun, R. (2002). Old age support in contemporary urban China from both parents' and children's perspectives. Research on Aging, 24(3), 337-359. doi: $10.1177 / 0164027502243003$

Trice, A. G. (2004). Mixing it up: International graduate students' social interactions with American students. Journal of College Student Development, 45, 671-687. doi: 10.1353/csd.2004 .0074

Wadhwa, V., Saxenian, A., Freeman, R. B., \& Salkever, A. (2009). Losing the world's best and brightest: America's new immigrant entrepreneurs, Part V. SSRN Electronic Journal. doi: 10.2139/ssrn.1362012

Wan, G. (2001). The learning experience of Chinese students in American universities: A cross-cultural perspective. College Student Journal, 35, 28 44. http://eric.ed.gov/?id=ED439653

Wang, C. D., \& Mallinckrodt, B. (2006). Acculturation, attachment, and psychosocial adjustment of Chinese/Taiwanese international students. Journal of Counseling Psychology, 53(4), 422-433. doi:10.1037/00220167.53.4.422

Ward, C., Bochner, S. \& Furnham, A. (2001). The psychology of culture shock (2nd ed.). London: Routledge.

Ward, H. H. (2015). Internationalization in action: Internationalizing the cocurriculum, part one-Integrating international students. American Council 
on Education. Retrieved from https://www.acenet.edu/news-room/ Pages/Intlz-in-Action-2015-March.aspx

Watt, S. K., Golden, M., Schumacher, L. A., \& Moreno, L. S. (2013). Courage in multicultural initiatives. New Directions for Student Services, 2013(144), 57-68. doi: 10.1002/ss.20069

Webber, K. L., Krylow, R. B., \& Zhang, Q. (2013). Does involvement really matter? Indicators of college student success and satisfaction. Journal of College Student Development, 54, 591-611. doi: 10.1353/csd.2013.0090

Wei, M., Heppner, P. P., Mallen, M. J., Ku, T., Liao, K. Y., \& Wu, T. (2007). Acculturative stress, perfectionism, years in the United States, and depression among Chinese international students. Journal of Counseling Psychology, 54(4), 385-394. doi: 10.1037/0022-0167.54.4.385

Williams, R., Leahy, A., \& Jensen, P. (2015). U21 ranking of national higher education systems. Retrieved from http://www.universitas21.com/ RelatedFile/Download/664

Yan, K., \& Berliner, D. C. (2011). Chinese international students in the United States: Demographic trends, motivations, acculturation features and adjustment challenges. Asia Pacific Education Review, 12(2), 173-184. doi: $10.1007 / \mathrm{s} 12564-010-9117-\mathrm{x}$

Yan, K., \& Berliner, D. C. (2013). Chinese international students' personal and sociocultural stressors in the United States. Journal of College Student Development, 54(1), 62-84. doi: 10.1353/csd.2013.0010

Yang, H. (1996). The distributive norm of monetary support to older parents: A look at a township in China. Journal of Marriage and the Family, 58(2), 404. doi: $10.2307 / 353505$

Ye, J. (2006). Traditional and online support networks in the cross-cultural adaptation of Chinese international students in the United States. Journal of Computer-Mediated Communication, 11(3), 863-876. doi: 10.1111/ j.1083-6101.2006.00039.x

Yeh, C. J., \& Inose, M. (2003). International students' reported English fluency, social support satisfaction, and social connectedness as predictors of acculturative stress. Counseling Psychology Quarterly, 16(1), 15-28. doi: 10.1080/095150703100011405

Yuan, W. (2011). Academic and cultural experiences of Chinese students at an American university: A qualitative study. Intercultural Communication Studies, 1, 141-158.

Zhang, S. Y., \& Carrasquillo, A. L. (1992). Chinese American students: A review of the literature. Retrieved from http://files.eric.ed.gov/fulltext/ ED369682.pdf

Zhang, Z., \& Brunton, M. (2007). Differences in living and learning: Chinese international students in New Zealand. Journal of Studies in International Education, 11(2), 124-140. doi: 10.1177/1028315306289834 
XIAOKANG TANG currently is a $\mathrm{PhD}$ student at University of Illinois Urbana-Champaign. Xiaokang's main research interest is focused on the role international students play in the internationalization of U.S. higher education, how international students adapt to their new life in the U.S. campuses, and what are some practices institutions perform to improve international students' experience. Email: xtang13@illinois.edu

DANIEL COLLIER, $\mathrm{PhD}$, is a recent alumnus of the University of Illinois at Urbana-Champaign and current post-doctoral research associate at the Center for Research on Instructional Change in Postsecondary Education at Western Michigan University in Kalamazoo, MI. Daniel researches higher education policy \& politics, how motivation and external factors (e.g. finances) influence student persistence, and how student loan debt affects post-college beliefs, behaviors, and health.

ALLISON WITT, PhD, is the Director of International Programs in the College of Education at the University of Illinois Urbana-Champaign where she teaches Global Studies in Education and is the Program Leader for the International Education Administration and Leadership program. She is the author of Shifting Tides in Global Higher Education (2011) published by Peter Lang. 